\title{
A EVOLUÇÃO DA AGROINDÚSTRIA EM UBERLÂNDIA (MG) / 1970-2014: ESPECIALIZAÇÃO E EXPANSÃO DAS INDÚSTRIAS PROCESSADORAS DE SOJA, CARNES E COUROS
}

\author{
Denise Leonardo Custodio Machado de OLIVEIRA ${ }^{1}$ \\ Silvia SELINGARDI-SAMPAIO²
}

\section{Resumo}

Neste artigo,analisa-se a evolução e a especializaçãoda agroindústria em Uberlândia (MG). A atividade agroindustrial, surgida em fins do século XIX, conheceu, no período pós-1970, intensos processos de expansão e especialização, haja vista os investimentos que o citado município passou a receber de grupos empresariais vinculados ao processamento de soja, carnes e couros. O destaque destas empresas, de capitais nacionais e internacionais, se deve ao fato de controlarem grandes unidades industriais pertencentes a ramos vinculados ao agronegócio, responsável pela grande projeção assumida pelo Brasil, desde a década de 2000, no mercado global de commodities.

Palavras-chave: Agroindústria. Uberlândia. Indústria de soja, carnes e couros.

\begin{abstract}
Evolution and specialization of agroindustry in Uberlândia (MG) /19702014: The expansion of soy, meat, and leather processing industries
\end{abstract}

This article analyzes the evolution and specialization of agroindustry in Uberlândia (MG). The agroindustrial activity that emerged at the end of the nineteenth century saw intense expansion and specialization in the post-1970 period, given the investments that the municipality received from business groups involved in the processing of soybeans, meats, and hides. The prominence of these companies' national and international capital is due to the fact that they control large industrial units belonging to branches linked to agribusiness, responsible for the great projection assumed by Brazil, since the 2000s, in the global commodities market.

Key words: Agroindustry. Uberlândia. Soybeans. Meats. Leather mills.

\footnotetext{
1 Doutora pelo Programa de Pós-Graduação em Geografia. IGCE - UNESP, Rio Claro. E-mail: denisecustodiooliveira@gmail.com

2 Professora Livre-Docente do Programa de Pós-Graduação em Geografia. IGCE- UNESP, Rio Claro. E-mail triesses@ig.com.br
} 


\section{INTRODUÇÃO}

Em um mundo cada vez mais urbanizado e com atividades econômicas em reestruturação, o tema"indústria" permanece atual e pertinente, motivando, no âmbito da Geografia Econômica, estudos sobre a dinâmica dos diversos espaços industriais, da escala local à global. Uberlândia, município localizado no Triângulo Mineiro/Alto Paranaíba, na porção oeste de Minas Gerais, com uma população estimada em 676.613 em 2017 (IBGE, 2017), caracteriza-se por uma economia diversificada, com múltiplas atividades.Neste contexto, tal localidade tem se revelado como um espaço econômico que instiga a investigação, desde quesua indústria sustenta parte significativa da economia local e da região, representando 35\% do PIB (IBGE, 2013), e apresenta certas feições próprias, dignas de exame mais detalhado.

A referida atividade caracteriza-se, por um lado, pelo predomínio do ramo alimentício e de pequenos estabelecimentos, e de outro, por um reduzido número de estabelecimentos de grande porte, pertencentes a empresas nacionais e estrangeiras, a maior parte agroindústrias, destacando-se as processadoras de soja, de carnes, e de couros.

Embora Uberlândia possua uma tradição agropecuária e agroindustrial, que deita suas raízes no século XIX, foi a partir dos processos de modernização e de industrialização da agricultura nacional, iniciados nas décadas de 1970 e 1980, como parte de políticas instituídas pelo governo federal e voltadas para a ocupação das áreas de cerrado, que o município passou a receber investimentos de grandes grupos empresariais, particularmente os vinculados ao processamento de grãos (soja), de carnes e de couros. Tal processo desenvolveu-se sob a ação do Estado, num contexto de forte expansão capitalista do espaço brasileiro, na qual alguns locais foram privilegiados, tal como Uberlândia.

Atualmente, algumas dessas empresas ainda se encontram situadas no referido município (Algar-Agro, Cargill, ADM, Brasil Foods e JBS Couros), destacando-se não somente pelo fato de comporem grandes unidades industriais, mas sobretudo por pertencerem a ramos vinculados ao agronegócio - conjunto de atividades muito expressivo ao longo de toda a evolução econômica do país -, o qual foi alçado, desde a década de 2000, a uma posição de importância máxima, responsável pela grande projeção assumida pelo Brasil, no mercado global de commodities.

Neste contexto, produtos dos chamados complexo soja (soja em grão,farelo e óleo de soja), complexo carnes (carne suína, de aves e bovina) e do segmento de couros aumentaram sua participação na pauta exportadora nacional. Conforme dados do Ministério da Agricultura, Pecuária e Abastecimento (BRASIL, 2016), a partir do início dos anos 2000, os produtos do complexo soja tornaram-se o principal item de exportação do país, cabendo ao complexo carnes,desde 2005, a segunda colocação, e ao segmento de couros também uma participação importante (embora menor em relação aos outros dois) na pauta exportadora nacional. Tal fato incide diretamente em localidades de tradição agrária e agroindustrial, a exemplo de Uberlândia.

É em meio a esse quadro geral que aqui se aborda a evolução e a especialização da agroindústria no município em foco, tendo como recorte temporal o período de 1970 a 2014.

Além da Introdução e Considerações Finais, o artigo se encontra estruturado em três partes. Na primeirasão apresentadas, de início, algumas noções conceituais atinentes ao tema, como o conceito de agroindústria e os processos de modernização e de industrialização da agricultura brasileira.Na segunda parte, faz-se uma breve caracterização da área de estudo e da dinâmica econômica local e, neste contexto, aborda-se a origem da agroindústria. Na terceira e última parte, considerada o núcleo 
central do artigo, analisa-se a atividade agroindustrial. Desta forma, certos fatos novos, mudanças e processos reconhecidos ao longo do recorte temporal considerado ensejam uma periodização em três fases, assim definidas: 1970-1984- "A modernização da agricultura"; 1985-1999- "Implantação de empresas agroindustriais nacionais e estrangeiras"; e 2000 até os dias atuais, "O aprofundamento da inserção no mercado globalizado de commodities".

Nas Considerações Finais são resgatadas as principais constatações permitidas pela pesquisarealizada, e são expostas reflexões a respeito das atuais conjunturas econômicas nacional e internacional, com óbvios reflexos em Uberlândia e em sua atividade agroindustrial.

\section{FUNDAMENTOS TEÓRICOS}

No contexto dos anos 1960 e 1970, paralelamente ao desenvolvimento industrial do país, o espaço rural brasileiro vivencia os efeitos da industrialização, através de dois eventos conceitualizados: a modernização e a industrialização da agricultura.

A modernização da agriculturabrasileira teria se iniciado já por volta dos anos 1950, com a importação de máquinas e insumos. Kageyama e outros (1990, p. 113) definem tal fato como uma "[...] mudança na base técnica da produção agrícola. É um processo que ganha dimensão nacional no pós-guerra, com a introdução de máquinas na agricultura (tratores importados), de elementos químicos (fertilizantes, defensivos) $[\ldots]^{\prime \prime}$.

Segundo Delgado (2012, p. 16), até 1960 os insumos modernos foram pouco empregados na agricultura, além de, em quase sua totalidade, terem que ser importados. Assim, somente na década seguinte é que o Brasil teria passado a produzir bens de capital voltados para o setor agrícola.O desenvolvimento da indústria de bens de capital teria resultado na industrialização da agricultura,a qual se verifica após 1965, significando que esta atividade

[...] está conectada com outros ramos da produção; para produzir ela depende dos insumos que recebe de determinadas indústrias; e não produz mais apenas bens de consumo final, mas basicamente bens intermediários ou matérias-primas para outras indústrias de transformação [...]. (KAGEYAMA et al., 1990, p. 114).

À medida em que o país substitui a importação de máquinas e equipamentos, os processos de modernização e de industrialização do campo brasileiro se intensificam. Os aludidos processos refletem eventos de ordem política e econômica ocorridos no pós-segunda guerra, tanto em nível nacional - como a forte ação do Estado que, no intuito de promover a industrialização do país, adota políticas de desenvolvimento - quanto na esfera externa, eventos tais como a internacionalização do capital financeiro e produtivo, e a nova divisão internacional do trabalho, ensejando a entrada de empresas multinacionais no Brasil.

Conforme Müller (1982, p. 24),diversas empresas estrangeiras passaram a atuar, por volta dos anos 1970, como "indústrias para a agricultura", as quais destinavam-se à produção de tratores, máquinas e implementos agrícolas, assim como à fabricação de fertilizantes e adubos, e, ainda, à produção de rações.

Os efeitos da industrialização da agricultura, portanto, incidem diretamente nas indústrias processadoras - as agroindústrias -, já que há um aumento na oferta de 
matérias-primas de origem agrícola.Müller (1981) define agroindústria, em sentido amplo, como unidade industrial de beneficiamento e/ou transformação de produtos de origem agrícola, a qual se insere, no contexto da moderna agricultura, nos chamados complexos agroindustriais.

Graziano da Silva (1993, p. 2) afirma que,na década de 1970, ocorreu a formação dos complexos agroindustriais(CAIs)no Brasil, "[...] a partir da integração intersetorial entre três elementos básicos: as indústrias que produzem para a agricultura, a agricultura (moderna) propriamente dita e as agroindústrias processadoras $[\ldots] . "$

Para Delgado (2012, p. 17), os complexos agroindustriais seriam uma "[...] faceta moderna da agricultura brasileira" e integram-se "[...] às múltiplas correntes do comércio internacional de produtos agrícolas e agroindustriais.". Em princípio concentrados, sobretudo, em áreas do sudeste e sul brasileiro, acabaram se disseminando, na década de 1980, também pela região centro-oeste.

Neste contexto, a utilização de modernas técnicas e de insumos na agricultura,bem como a introdução de novos cultivos - como, por exemplo, a soja -, particularmente em espaços de tradição agropecuária, acabaram atraindo a implantação de empresas agroindustriais, nacionais e estrangeiras. Alguns municípios do Triângulo Mineiro/Alto Paranaiba constituem exemplos destes espaços, nos quais a estreita "relação agricultura-indústria" ensejou, nas décadas de 1970 e 1980, a formação de complexos agroindustriais. Ao especializaram-se produtivamente em determinados segmentos - como o de grãos, de carnes e de couros -, tais espaços formaram uma estrutura que Ihes permitiu expandir muito sua produção, a partir dos anos 2000, a fim de atender à demanda internacional de commodities.

Essa evolução interna ocorreu paralelamente, e de forma integrada, ao desenvolvimentodo mercado mundial de commodities, o qual, obviamente, responde por grande parte dos estímulos à produção brasileira que visa à exportação e, também, pelos momentos de retração de sua demanda. Não é exagero dizer que a produção brasileira de commodities pulsa ao ritmo da demanda global.

Com o aprofundamento da participação do Brasil no comércio de commodities, as atividades agrícola e agroindustrial voltadas para exportação se inserem no setor do agronegócio, o qual, grosso modo,pode ser definido "[...] como a soma de quatro segmentos: (a) insumos para a agropecuária, (b) produção agropecuária básica ou, como também é chamada, primária ou "dentro da porteira", (c) agroindústria (processamento) e (d) distribuição". (CENTRO DE ESTUDOS AVANÇADOS EM ECONOMIA APLICADA-CEPEA, 2015).

Considerando-se o cenário de expansão das exportações primárias que se descortina a partir de 2000, no contexto da globalização econômica, pode-se compreender o agronegócio como um segmento que abrange as várias atividades produtivas responsáveis pela produção e comercialização de gêneros agropecuários e agroindustriais, estrategicamente articulado ao capital e aos interesses dos grandes grupos econômicos e financeiros. Como se verá, a evolução da atividade agroindustrial do município de Uberlândia, a partir de 1970, redundou, em período mais recente, em sua inserção no comércio mundial de commodities agrícolas e agroindustriais. 


\section{O MUNICÍPIO DE UBERLÂNDIA: CONSIDERAÇÕES SOBRE A DINÂMICA ECONÔMICA LOCAL E A GÊNESE DA AGROINDÚSTRIA}

O desenvolvimento econômico de Uberlândia deu-se, ao longo de sua trajetória, através da influência tanto de fatores endógenos (aqueles que se desenvolveram ou que são inerentes ao local) quanto exógenos (cujas causas são externas). No tocante aos primeiros, pode-se dizer que a prosperidade de Uberlândia se deve, em grande medida, à posição geográfica e à infraestrutura de transportes, fatores estes que, historicamente, têm favorecido o desenvolvimento da economia local. Guimarães (2010, p. 80-81) demonstra que, nas primeiras décadas do século XX, o município já apresentava a condição de entroncamento rodoferroviário, além de consolidar sua função de "principal entreposto comercial regional".

Soares e outros (2010, p. 168) destacam as vias de circulação e o entroncamento que se formou a partir delas,como um dos fatores que consolidaram Uberlândia como "centro regional", sendo, portanto, fundamental na expansão das atividades econômicas.

Território de passagem,interligando os estados de São Paulo, Goiás e o Distrito Federal, assim como Minas Gerais, Mato Grosso do Sul e Goiás, pode-se dizer que a posição geográfica desfrutada por Uberlândia funcionou como um "recurso do território", o qual foi como que "ativado" ao longo do processo de desenvolvimento econômico local e nacional. Tratar-se-ia de uma "vantagem locacional", que confere ao município uma especificidade territorial (Figura 1).

Além da posição geográfica, Soares e outros (2010) também consideram o papel exercido pela elite local como decisivo para o desenvolvimento do município. Pode-se dizer que apresença de capitais locais, aliada (muitas vezes pertencente) a uma elite "de espírito empreendedor", consistiram em fatores que estimularam investimentos em diversos setores, tal como o agroindustrial, através de empresas surgidas nos anos 1960 e 1970.

Por outro lado, fatores exógenos, que abrangem a chegada da ferrovia, em fins do século XIX, as políticas do governo central de incentivo à modernização e industrialização da agricultura das áreas de cerrado, e os investimentos de capitais de origem nacional e estrangeira, muitos dos quais voltados para o setor agroindustrial, a partir dos anos 1980, também estimularam o desenvolvimento econômico local. Mais recentemente, desde os anos 2000, as políticas de fomento ao agronegócio, além da crescente demanda, sobretudo da China, e da alta valorização de commodities agrícolas e agroindustriais no mercado internacional, também consistiram em fatores externos de grande influência na economia do município.Em meio a tais eventos, verifica-se tanto uma evolução quanto uma expansão da agroindústria no espaço local.

As origens da atividade agroindustrialno município podem ser reconhecidas já no século XIX, quando, segundo Pessôa (1982), em meio ao desenvolvimento da agropecuária, surgem atividades fabris, sendo que a pioneira teria sido uma ferraria, fabricante de instrumentos para o setor agrícola. Martins (2000, p. 65), ao analisar a gênese da indústria uberlandense, afirma que "As manufaturas, instaladas em Uberlândia ainda no final do século XIX, realizavam beneficiamento de produtos agrícolas e pecuários (produzidos localmente ou vindos de outras regiões), para sua posterior comercialização". Os primeiros estabelecimentos industriais surgiram a partir da manufatura e do capital acumulado através do comércio, voltados, sobretudo, para a transformação de produtos agropecuários (beneficiamento de arroz, fábrica de banha, curtumes), além de fábricas de móveis e calçados, cerâmica, dentre outros. 


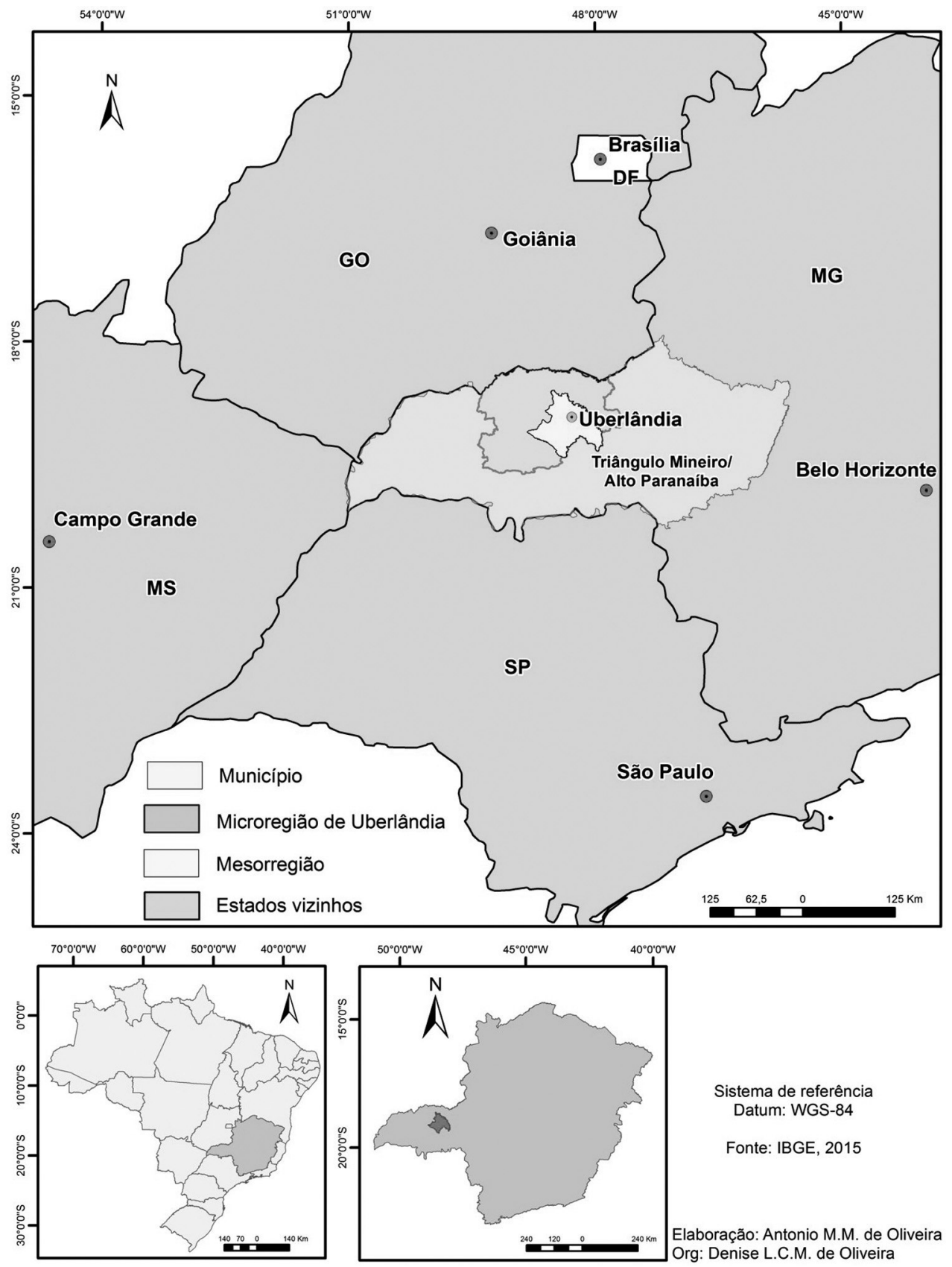

Figura 1 - Localização do município de Uberlândia, M.G. 
A indústria nascente apresentava, pois, "[...] um alto grau de complementariedade com a agricultura [...]", já que "[...] pequenas unidades industriais produziam bens que eram utilizados na produção agrícola (ferragens para carros, facas, foices, machados) e transformavam produtos agrícolas (produção de tecidos a partir da lã e do algodão, engenho de cana)". (MARTINS, 2000, p. 65) em bens de consumo. Tal complementariedadee interação vieram a se refletir, posteriormente, no desenvolvimento e no fortalecimento da agroindústria nas economias local e regional, especialmente a partir do último quartel do século $\mathrm{XX}$, fato a ser abordado a seguir.

\section{PERIODIZAÇÃO DA ATIVIDADE AGROINDUSTRIAL EM UBERLÂNDIA: 1970- 2014}

\section{- Primeiro Período - 1970 /1984 - A modernização da agricultura}

O desenvolvimento agroindustrial do município de Uberlândia adquire um novo dinamismo a partir dos anos 1960-70, refletindo as mudanças ocorridas na agricultura regional e nacional.

As áreas de cerrado e, portanto, as do Triângulo Mineiro e Alto Paranaiba, incluem-se nos espaços agrícolas do território nacional que, estrategicamente, foram incorporados à expansão capitalista no campo. Tal quadro delineou-se no contexto de ocupação das chamadas "fronteiras agrícolas", e de modernização da agricultura.

Para Cleps Júnior (1998, p. 125), "A expressão física principal das 'fronteiras' consiste numa reorganização do espaço pela intensificação da produção agrícola ou da ocupação demográfica em zonas consideradas como 'vazias', segundo critérios geralmente subjetivos". Neste sentido, a ação do Estado se faz presente, haja vista o papel das políticas implementadas pelos governos federal e estadual de incentivo à ocupação de áreas de cerrado, fundamentais para que ocorressem mudanças na produção agropecuária (por exemplo, com a introdução de monoculturas como a soja).

No contexto do processo de modernização agrícola regional e nacional, o espaço agrário uberlandense também se modernizou, fato primeiramente analisado por Pessôa (1982), a qual elenca alguns aspectos que caracterizariam tal processo no município, quais sejam: aumento na utilização de tratores e de arados;crescente utilização de sementes melhoradas, fertilizantes e defensivos;diminuição da força humana e crescimento da força mecânica na agricultura, através do uso de tratores; desenvolvimento das vias de transporte, facilitando o contato com municípios difusores de modernas tecnologias;sistema de armazenagem de produtos agropecuários, 0 qual aumentou consideravelmente a partir dos anos 1960, caracterizando o município como entreposto comercial.Além disso, houve a implantação da Associação de Crédito e Assistência Rural (ACAR), em 1964, com programas de crédito e de extensão rural (os quais foram continuados, a partir de 1975, pela EMATER- Empresa de Assistência Técnica e Extensão Rural do Estado de Minas Gerais), bem como de uma unidade do POLOCENTRO (Programa de Desenvolvimento dos Cerrados).

A referida autora considera o período de 1950-1975 como uma segunda etapa de desenvolvimento rural de Uberlândia $^{3}$, cujas características principais, seriam, além

\footnotetext{
3 A primeira teria iniciado em 1920.
} 
da introdução de modernos insumos agrícolas, a expansão da lavoura temporária, sobretudo, através da introdução da sojicultora, e o aumento das áreas ocupadas com pastagens. Apesar da manutenção de cultivos tradicionais, a soja é introduzida no município, devido à crise do café, algodão e amendoim. (PESSÔA, 1982, p. 55).

Tal quadro teria se delineado num contexto de intensa migração campo-cidade e do processo de industrialização do município. Assim, ainda de acordo com Pessôa(1982, p. 89), as grandes transformações na agricultura uberlandense teriam ocorrido em função também da industrialização e do desenvolvimento do setor terciário, embora tenham sido possibilitadas, sobretudo, pela posição geográfica do município.

Desta forma, percebe-se que a posição geográfica- fator endógeno fundamental, desde o período de formação econômica e territorial - e as consequentes relações propiciadas ao município com outras localidades, intra e interregionalmente, permanecem como um importante recurso do território, a beneficiar as diversas atividades econômicas, dentre as quais a agricultura. Por outro lado, o processo de industrializaçãodesenvolve-se de forma ainda bastante atrelada às atividades agrícola e pecuária, haja vista as empresas agroindustriais que se instalam, nesta fase, no espaço local.

O período em tela é iniciado em 1970, por tratar-se do ano a partir do qual a agroindústria se expande, e a soja é introduzida no município. No nosso entendimento, trata-se de um marco temporal no processo de agroindustrialização, desde que a disseminação desta cultura motivará a instalação de indústrias processadoras de grãos, nos períodos posteriores. Contudo, tal processo já havia sido impulsionado, na década anterior, com a implantação, em 1962, da CALU - Cooperativa Agropecuária Limitada de Uberlândia, indicando que, em princípios da década de 1960, os vínculos do setor primário com a atividade industrial se faziam presentes em relação à produção leiteira. Destinada à aquisição e distribuição do leite produzido em Uberlândia e municípios vizinhos, a CALU fabricava queijos, manteiga e outros produtos derivados. (PESSÔA, 1982, p.121-123). (Quadro 1).

Como observado no quadro 1, em 1964 houve a instalação das granjas Rezende e Planalto, voltadas para o setor avícola, tendo a primeira uma atuação decisiva, nas décadas seguintes, para que se consolidasse o complexo de carnes no município.

Nesta época, houve a criação da "Cidade Industrial" em 1965, e a instalação do Distrito Industrial em 1971, atraindo investimentos locais e externos ao município (MARTINS, 2000). Em 1970, surge a Cocal Alimentos e, em 1973, tem-se a implantação de uma filial da empresajaponesa Daiwa, de preparação e fiação de fibras de algodão. Em 1978, duas empresas foram implantadas, a ABC de Minas (de origem local), a princípio voltada para o processamento de algodão, e, posteriormente (como se verá, na fase seguinte), para o de grãos, e a Souza Cruz, do ramo de fumo, de origem nacional. (Quadro 1).

É a partir desta fase que se estruturam os chamados Complexos Agroindustriais (CAIS), entre os quais se destaca o complexo soja, que, conforme Cleps Júnior (1998, p. 151), "[...] tornou-se o símbolo da modernização agroindustrial no Brasil".

A partir dos anos 1980, os setores de grãos e de carnes consolidam-se no município, tanto através da reestruturação de empresas já instaladas em décadas anteriores, como pela implantação de outros estabelecimentos, nacionais e estrangeiros. Além disso, também o ramo de couros recebe novos investimentos, questões a serem abordadas no próximo segmento. 


\section{Quadro1- Uberlândia - principais agroindústrias por ano de instalação, ramos e produtos - Décadas de 1960 e 1970}

\begin{tabular}{|l|c|l|}
\hline \multicolumn{1}{|c|}{ Empresa } & $\begin{array}{c}\text { ano de } \\
\text { instalação }\end{array}$ & \multicolumn{1}{|c|}{ Ramo/produto (s) } \\
\hline $\begin{array}{l}\text { Cooperativa Agropecuária Ltda. } \\
\text { de Uberlândia (CALU) }\end{array}$ & 1962 & Alimentício/leite e derivados \\
\hline Granja Planalto & 1964 & Avicultura \\
\hline Granja Rezende & 1964 & Avicultura \\
\hline Cocal Alimentos & 1970 & $\begin{array}{l}\text { Alimentício/beneficiamento } \\
\text { de arroz }\end{array}$ \\
\hline Daiwa do Brasil & 1973 & $\begin{array}{l}\text { Têxtil/Preparação e fiação } \\
\text { de fibras de algodão }\end{array}$ \\
\hline ABC de Minas & 1978 & $\begin{array}{l}\text { Têxtil/Processamento de } \\
\text { algodão }\end{array}$ \\
\hline Souza Cruz & 1978 & $\begin{array}{l}\text { Fumo/Processamento de } \\
\text { fumo }\end{array}$ \\
\hline
\end{tabular}

Fonte: Empresas do Brasil (2016); Pesquisa direta

Elaborado por Denise L.C.M.de Oliveira

\section{- Segundo Período - 1985/1999 - Implantação de empresas agroindustriais nacionais e estrangeiras.}

Conforme Pessôa (1982), no início dos anos 1980, a economia do município ainda se sustentava na atividade agropecuária e nas unidades de beneficiamento de produtos primários. A autora deixa claro tal quadro, ao afirmar que

Como município integrante do Triângulo Mineiro, Uberlândia tem ainda hoje, na agropecuária, e nas indústrias decorrentes das atividades rurais, a base de sua economia. Assim, destacam-se os cultivos e beneficiamento do arroz, milho, e mais recentemente, da soja. O cultivo da soja vem evoluindo nos últimos três anos de maneira explosiva nas regiões do Triângulo Mineiro e Alto Paranaíba. (PESSÔA, 1982, p. 53).

Em relação ao cultivo da soja, é a partir do início desta fase, ou seja, 1985, que tal cultura registra um maior incremento no município. Conforme dados do Instituto de Pesquisas Econômicas Aplicadas (IPEADATA, 2015), no citado ano a produção de soja alcança 27 mil toneladas, contrastando com o período anterior, no qual a quantidade produzida não ultrapassou 11 mil toneladas. Nos anos seguintes, a produção da soja cresceu de forma contínua, refletindo a expansão da atividade agroindustrial, analisada a seguir.

No tocante a esta, pode-se dizer que tal período caracterizou-se, pela consolidação dos segmentos de grãos e de carnes. Assim, ocorre a implantação de um grande estabelecimento multinacional, a Cargill (em 1986) e também a reorganização técnico-produtiva de unidades já existentes, como a ABC (atual Algar Agro, em 1985), voltadas para o processamento de grãos. Além das referidas empresas, nesta fase (como se verá a seguir) também a Rezende Alimentos (Granja Rezende) passou a se dedicar ao processamento de soja e fabricação de ração (Quadro 2). 


\section{Quadro 2 - Uberlândia - principais agroindústrias por ano de instalação, ramos e produtos - Décadas de 1980/1990}

\begin{tabular}{|l|l|l|}
\hline ABC de Minas/Algar Agro & 1985 & \multicolumn{1}{c|}{ Processamento de soja } \\
\hline Frigorífico Luciana & 1985 & Alimentício/Abate de bovinos e suínos \\
\hline Cargill & 1986 & Alimentício/Processamento de grãos \\
\hline Braspelco/Xinguleder & 1986 & Couros/curtimento de couro \\
\hline Brasfrigo* & 1990 & Alimentício/Processamento de vegetais \\
\hline Frigorífico Real & 1993 & Alimentício/Abate de bovinos \\
\hline Frigorífico São Pedro & 1996 & Alimentício/Abate de suínos \\
\hline Laticínio Uberleite & 1997 & Alimentício/Laticínios \\
\hline Sabor de Minas & 1999 & Embutidos \\
Fonte: Empresas do Brasil (2016); *Pesquisa direta \\
Elaborado por Denise L.C.M. de Oliveira
\end{tabular}

A instalação destas empresas deu-se num período em que, conforme Müller (1982, p. 33), o complexo soja ainda era recente no país, apesar de caracterizar-se por um "[...] elevado grau de internacionalização, constituindo-se, por isso mesmo, na mais expressiva manifestação da revolução agrária em curso no país". (grifo do autor).

Segundo Cleps Júnior (1998, p. 141-142), a instalação de grandes empresas dos ramos de grãos e de carnes, na região Centro-Oeste e em outras áreas de cerrado, teria ocorrido na segunda metade dos anos 1980. Nesta década, houve a implantação de programas de apoio ao desenvolvimento agroindustrial destas áreas, particularmente ao setor de grãos, alguns destes financiados pelo BNDES (Banco Nacional de Desenvolvimento Econômico e Social). Entretanto, o final da referida década caracterizou-se pela diminuição de crédito estatal e aumento de recursos privados.

Neste sentido, entre 1989 e 1993, foram lançados o Programa Nacional de Desenvolvimento Rural (PNDR), o qual colaborou para a consolidação da agropecuária de grãos "em bases empresariais e modernas", e o Programa Nacional de Desenvolvimento Agroindustrial (PNDA), voltado para indústrias processadoras e outras do ramo alimentício. (CLEPS JÚNIOR, 1988, p. 145).

No caso da soja, conforme o autor supracitado (p. 161), teria havido um verdadeiro "boom" nas áreas de cerrado, em função de algumas vantagens obtidas, tais como maior produtividade e melhor qualidade, incentivos fiscais oferecidos, por parte de alguns Estados, para a implantação de indústrias, além da possibilidade do produtor ruraldepositar a soja diretamente nos armazéns das agroindústrias, permitindo redução de custos.

Segundo Cleps Júnior (1998, p. 202), no município de Uberlândia, em fins da década de 1990, o complexo soja encontrava-se estruturado por três empresas, ABC, Rezende e Cargill, cujas capacidades de processamento de soja somadas alcançavam 1.720.000 toneladas por ano.

Em relação ao setor de carnes, de acordo com o quadro 2, observa-se que houve a implantação de quatro estabelecimentos, Frigorífico Luciana, em 1985, Frigorífico Real, em 1993, Frigorífico São Pedro, em 1996, e Sabor de Minas Alimentos, em 1999.

Contudo, cabe aqui abordar a Rezende Alimentos (antiga Granja Rezende), cuja atuação, nesta fase, foi decisiva para que se consolidasse o complexo de carnes no município. 
Cleps Júnior (1998) analisou a atuação desta empresa, especialmente quanto à reestruturação produtiva ocorrida a partir dos anos 1980. Segundo o autor, a então Granja Rezende, voltada para a produção de matrizes, até fins dos anos 1970 possuía uma fábrica de rações, um abatedouro de aves e um incubatório para a produção de aves de corte. A partir de 1978, passou a incluir todos os segmentos da avicultura de corte (da criação ao abate).

Entretanto, após enfrentar dificuldades financeiras, a partir de 1986, a empresa reestrutura-se, ampliando suas instalações, tais como granjas e abatedouro de aves (o qual foi também modernizado), e construindo um novo incubatório. Além disso, houve a implantação de um abatedouro de suínos e de bovinos, o que demonstra uma inovação em sua linha de produtos, a que o autor se refere como "diversificação horizontal". Neste sentido, institui um programa de melhoramento genético, voltado para a criação de suínos.

Por outro lado, a empresa passou a desenvolver, também, um "processo de verticalização", vindo a atuar tanto no processamento de soja, como no de carnes.

\begin{abstract}
O processo de verticalização, ou seja, a diversificação "para trás" (na soja e rações) e "para frente" (industrialização de produtos alimentares finais como subprodutos da soja e carnes) da Rezende Alimentos nasceu da sua atuação na venda de matrizes, da criação própria e abate de aves e na produção de rações a partir da soja e milho. Vislumbrando também a tendência de diminuição no mercado de aves de corte (pintos de um dia), uma vez que as empresas do segmento passam pelo mesmo processo de diversificação, a Rezende ingressa no ramo da produção agroalimentar de gêneros finais de consumo, como os produtos derivados de carnes. (CLEPS JÚNIOR, 1998, p. 211, grifos do autor).
\end{abstract}

Assim, o estabelecimento passou a atuar tanto no complexo grãos-farelo-óleo quanto no de grãos-rações-carnes. Ainda segundo Cleps Júnior (1998, p. 209), em 1996, a empresa "[...] figurava no ranking das maiores organizações em Patrimônio Líquido, aparecendo em $44^{\circ}$ lugar entre os 300 maiores grupos do Brasil, [..] atuando nos setores de Carne e Pecuária, Alimentos e Transporte e Armazenagem." Desta forma, encontrava-se estruturada em quatro estabelecimentos, a Granja Rezende S.A, Rezende Alimentos S.A, Rezende Óleo Ltda. e Rezende Armazéns Gerais. A atuação nos ramos de carnes bovina e suína concretiza-se em 1997, com a inauguração de um novo frigorífico. Por conseguinte, certamente não foi ao acaso que o efetivo de suínos apresenta um substancial aumento a partir de então, saltando de um total de 45 mil cabeças no referido ano, para 293 mil cabeças em 1999. (IPEADATA, 2015)

Apesar de toda esta reestruturação, a Rezende ainda manteve, até os anos 1990, a liderança nas vendas de matrizes de corte para empresas como a Chapecó, Frangosul, Perdigão e Sadia (as quais adquiriam as aves de um dia para os seus produtores integrados). (CLEPS JÚNIOR, 1998, p. 209).

Entretanto, em 1999, o Grupo Sadia, grande empresa de capital nacional, voltada para os ramos de carnes e ração, ao encontrar uma estrutura técnica e produtiva favorável criada pela Rezende, adquire as instalações desta empresa (SADIA, 1999), iniciando suas atividades no município, no ano seguinte.

Tal fato permite considerar o ano de 2000, portanto, como o início de um novo período no setor agroindustrial uberlandense, tanto pelo ingresso da Sadia, como pelo surgimento da ADM do Brasil, empresa multinacional processadora de soja. Além disso, o crescimento da economia do agronegócio no país, especialmente após 2004, 
particularmente no tocante ao comércio de commodities como as do complexo soja e de carnes, reforça a especialização produtiva do território local na produção destes gêneros, e a articulação do mesmo à esfera global.

Ainda com respeito ao segundo período, ocorreu a instalação da empresa Braspelco (Brasil Peles e Couros), de capital nacional, instalada em 1986, em função de Uberlândia situar-se em região de tradição pecuária. (Quadro 2). A esse respeito, é importante destacar o aumento registrado no efetivo de bovinos no município (que passou de 207 mil cabeças, em 1986, para 237 mil cabeças, em 1992(segundo IPEADATA, 2015), possivelmente como reflexo da instalação desta unidade processadora de couros no espaço local. Empresa de grande porte, cuja matriz se localizava neste município, chegou a ter 19 filiais distribuídas pelo território nacional. A importância do segmento de couros na pauta exportadora do município, sobretudo na primeira metade da década de 2000 , certamente se deve à atuação desta empresa, cuja magnitude pode ser avaliada pelo seu faturamento em 2003, que chegou a US $\$ 240$ milhões de dólares, sendo considerada a maior empresa exportadora deste ramo no país. (BRASPELCO..., 2003).

\section{- Terceiro Período - 2000 até os dias atuais - O aprofundamento da inserção no mercado globalizado de commodities}

Em meio à trajetória econômica trilhada pela economia brasileira no período em tela, voltada para a política de fomento ao agronegócio, alguns territórios locais passam a ser cada vez mais articulados ao comércio global de commodities. Assim sendo, esta nova fase liga-se a fatores externos ao município, a saber, a grande demanda que a China passou a exercer no mercado mundial de commodities agrícolas e semi-industrializadas, a partir de 2000, com consequente grande elevação de seus preços, e a política macroeconômica adotada pelo Brasil, após 2003, baseada na geração de grandes saldos comerciais a partir das exportações ampliadas de tais produtos.

Como pode ser observado no quadro 3, em Uberlândia, a nova fase de agroindustrialização iniciada a partir de 2000, caracteriza-se pela implantação de estabelecimentos vinculados ao agronegócio de carnes e de soja, que correspondem à Sadia S/A e à ADM do Brasil (tendo ambas iniciado suas atividades no começo do período em questão). Posteriormente, em 2009, as instalações da Sadia foram incorporadas pela Brasil Foods (BRF), um dos grandes grupos empresariais de origem nacional.

Outros ramos de empresas agroindustriais instalados foram representados pela Itambé em 2004, e a Cooperativa dos Produtores Rurais do Triângulo M./Alto Paranaíba (COTRIAL), em 2006, (ambas de laticínios), e a TCMA Algodoeira, em 2007 (de fiação de algodão).

Também neste período foram instaladas duas unidades do grupo JBS, uma voltada para a fabricação de conserva de vegetais (JBS Vegetais, atualmente extinta) e outra para o ramo de curtimento de couro - JBS Couros, respectivamente implantadas em 2004 e 2010. (Quadro 3). 


\section{Quadro 3- Uberlândia - principais agroindústrias por ano de instalação, ramos e produtos - Década de 2000}

\begin{tabular}{|l|c|l|}
\hline Sadia* & 2000 & $\begin{array}{l}\text { Alimentício/abate de aves, suínos e } \\
\text { processamento de carnes }\end{array}$ \\
\hline ADM do Brasil & 2002 & $\begin{array}{l}\text { Alimentício/processamento, refino e } \\
\text { envase de óleo de soja }\end{array}$ \\
\hline Itambé & 2004 & Alimentício/laticínios \\
\hline JBS Vegetais & 2004 & $\begin{array}{l}\text { Alimentício/fabricação de conservas } \\
\text { de legumes e outros vegetais }\end{array}$ \\
\hline $\begin{array}{l}\text { Triângulo Mineiro Açúcar e } \\
\text { Álcool }\end{array}$ & 2006 & Biocombustível/álcool \\
\hline $\begin{array}{l}\text { Cooperativa dos Produtores } \\
\text { Rurais do Triângulo M./Alto } \\
\text { Paranaíba (COTRIAL) }\end{array}$ & 2006 & Alimentício/Preparação do Leite \\
\hline TCMA Algodoeira & 2007 & $\begin{array}{l}\text { Preparação e fiação de fibras de } \\
\text { algodão }\end{array}$ \\
\hline Brasil Foods (BRF) & 2009 & $\begin{array}{l}\text { Alimentício/ abate de aves, suínos } \\
\text { e processamento de carnes }\end{array}$ \\
\hline JBS Couros & 2010 & Processamento de couros \\
\hline
\end{tabular}

Fonte: Empresas do Brasil (2016), *Dalla Costa (2009).

Elaborado por Denise L.C.M. de Oliveira

No tocante às agroindústrias do complexo soja, destaque-se que a atuação destes estabelecimentos envolve vínculos com a atividade agrícola não somente em nível local, mas também regional. Neste sentido, Pereira (2012, p. 86) analisa a atuação das empresas do setor de grãos (Cargill, ADM, Bunge e Algar-Agro) no Triângulo Mineiro/Alto Paranaíba, região que considera como "[...] um espaço estratégico para grandes tradings estrangeiras e também nacionais $[\ldots]$ ". Conforme o autor (p. 86),

[...] a moderna produção agrícola da região só ocorre pela presença de empresas que, não se envolvendo diretamente na atividade de plantio, realizam, no entanto, o trabalho de comercialização (compra e venda) e processamento do que é produzido (este é o caso das tradings Cargill, ADM, entre outros grupos), criando nexos de dependência entre produtores e agentes que comercializam a produção.

Assim sendo, o município de Uberlândia, ao sediar unidades de algumas das principais indústrias processadoras de grãos atuantes no país, "[...] desempenha a função de centro agroindustrial [...]tornando-se o centro polarizador e de convergência de grande parte da produção agrícola regional". (PEREIRA, 2012, p. 88-90).

Além das indústrias processadoras, Uberlândia se destaca no contexto regional, ainda segundo o mesmo autor (p. 91), ao agregar

[...] um conjunto de empresas que dão suporte técnico (infraestruturas de armazenamento, produção e revendas de sementes, veículos especiais e insumos), financeiro (é importante centro para a tomada de crédito) e científico (divide com Uberaba a direção executiva de um Arranjo Produtivo Local de Biotecnologia que envolve empresas voltadas para o agronegócio. 
Assim, no período em foco, houve a implantação, em Uberlândia, de duas unidades de empresas multinacionais da área de biotecnologia, a Monsanto e a Syngenta, as quais vinculam-se à produção agrícola de grãos, destacando-se a soja.

A expansão e a magnitude do segmento de soja, no município, na década de 2000, podem ser avaliadas também com base na evolução da sojicultura, cuja produção manteve a tendência ao crescimento praticamente contínuo, registrado na década anterior, passando de 84 mil toneladas, em 2001, para 131 mil, em 2005 (época do boom das commodities), totalizando, ao final da década, 144 mil toneladas de grãos. (IPEADATA, 2015).

Em Uberlândia, o complexo carnes já se encontrava estruturado anteriormente à fase em questão (através da Granja Rezende), entretanto, a implantação da Sadia, a partir de 2000, sem dúvida, veio a alicerçar tal segmento, haja vista tratar-se de uma empresa de projeção nacional e internacional, atuante, inclusive, como multinacional em outros países. Em relação ao complexo soja, o mesmo também já se encontrava formado - pela atuação da Algar-Agro, Cargill e da própria Rezende , contudo, a implantação da ADM em 2002, fortaleceu a concentração agroindustrial deste setor, por certo ampliando - juntamente com a presença da Sadia - o vínculo carnes/grãos no espaço local.

Apesar do ramo de carnes não ser novo no município, a vinda da Sadia marcou o início de uma nova fase de desenvolvimento agroindustrial. A importância assumida pelo complexo carnes na pauta exportadora do país - constituindo-se, desde 2001 , num dos principais itens de exportação, oscilando entre o segundo e o terceiro lugares (BRASIL, 2016) - refletiu-se nos espaços ocupados pelo setor de carnes, tal como no município em estudo.

Contudo, analisando-se o setor de carnes do município, no tocante à produção avícola, verifica-se que o efetivo de galináceos pouco evoluiu ao longo da década de 2000, registrando um incremento apenas em 2001 (quando atingiu o pico de 14,5 milhões de cabeças), não ultrapassando, nos anos seguintes, o total de 60 milhões de aves. Por outro lado, no tocante à suinocultura, como já destacado, houve uma evolução desde 1999, mantendo-se um crescimento praticamente ininterrupto, nos anos seguintes (período, portanto, em que a Sadia passou a atuar no município), atingindo, em 2007, um total de aproximadamente 650 mil cabeças. (IPEADATA, 2015).

Em relação ao ramo de couros, o mesmo já se destacava desde os anos 1980 , através da Braspelco, a qual atuou até aproximadamente fins da década de 2000, quando teria arrendado suas instalações para a unidade do grupo JBS, a JBS Couros. A importância deste segmento, no período em foco, não significou, entretanto, um maior incremento na pecuária do município, pois o número efetivo de bovinos manteve-se semelhante ao das décadas anteriores (em torno de 230 mil cabeças de gado). (IPEADATA, 2015).

Há que se destacar ainda, quanto ao período em análise, a participação do municípiono comércio internacional, e a atuação de algumas empresas agroindustriais nas exportações de commodities. Mediante informações do Dataviva (2016), referente à pauta exportadora do município entre 2000 e 2014, verificou-seque as exportaçõesabrangeram, predominantemente, produtos básicos (soja em grão, carnes in natura, café, milho,e outros) e semimanufaturados (couros curtidos, couros preparados, farelo e óleo de soja, açúcar em bruto, e outros). Contudo, os principais produtos exportados consistiram no complexo soja, no ramo de couros e também no complexo carnes (embora com menor participação), os quais, ao longo dos anos, muito expandiram sua participação nas exportações.

No tocante à atuação das agroindústrias no comércio de commodities, informações obtidas pelo Cadastro Industrial de Minas Gerais (CIEMG, 2013),por pesquisa 
direta, e também pelos sites das empresas (além de outros documentos eletrônicos), revelaram a participaçãotanto de estabelecimentosinstalados no período anterior (Cargill e Braspelco), como daqueles implantados na fase atual (Sadia/Brasil Foods, ADM e JBS Couros).

Assim, pode-se dizer que o florescimento da economia do agronegócio no paísintensificou a especialização produtiva local em gêneros agropecuários e agroindustriais. Durante o período abordado, as exportações destinaram-se a vários continentes e países (DATAVIVA 2016), o que evidencia a articulação de Uberlândia ao mercado global de commodities.

\section{CONSIDERAÇÕES FINAIS}

A análise aqui realizada, da evolução da agroindústria de Uberlândia, com base nos três períodos mais dinâmicos,após 1970, permitiu a constatação de que a referida atividade desenvolveu-se mediante uma conjunção de fatores endógenos e exógenos ao local. De um lado, a posição geográfica favorável e a excelente estrutura viária que se formou a partir dela, além da presença de capitais e de uma elite empreendedora local, foram fatores decisivos para o desenvolvimento da atividade agroindustrial. De outro, processos cuja origem é externa ao município, destacando-se a modernização agrícola, a implantação de agroindústrias nacionais e estrangeiras (como parte de políticas do governo federal voltadas para a ocupação das áreas de cerrado) e o aprofundamento da inserção brasileira no comércio de commodities, refletindo o processo de globalização da economia e o boom de tais produtos após 2000, foram fundamentais para a evolução e expansão da agroindústria. Tais fatores conferiram ao município aspectos que o caracterizam como um espaço agrário e agroindustrial, dando-lhe uma forma que, embora não seja exclusiva (já que congrega também várias atividades), se mantém na atualidade com muita importância.

Os dois primeiros períodos enfocados - 1970/1984 e 1985/1999 -, caracterizados pela modernização agrícola local e regional, pela expansão das atividades agropecuária e da agroindústria (tanto pela instalação de novos estabelecimentos quanto pela reestruturação e ampliação dos já existentes), podem ser compreendidos, pois, como uma fase de "maturação" da atividade agroindustrial, de maneira que, ao adentrar o século XXI, o espaço local estivesse estruturado, "formado", para intensificar sua função agropecuária e agroindustrial, apto a atender ao crescimento da demanda por commodities, tais como as de soja, couros e carnes.

$\mathrm{Na}$ presente fase (pós 2000), os "objetos" implantados (as empresas agroindustriais) se coadunam àqueles já existentes, em um espaço cuja forma "agrária e agroindustrial", já estabelecida em períodos precedentes, permanece, e cuja função produtiva de gêneros primários e semimanufaturados é reforçada e revitalizada, porém, em um cenário de globalização da produção e dos mercados. Portanto, o que há é uma mudança na escala geográfica à qual o território se articula, que consiste na escala global.

O município, ao abrigar "novos" e "antigos" atores econômicos e demais agentes do território (empresas agroindustriais, produtores rurais, sindicatos, poder público), cujas ações vinculam-se ao "moderno agronegócio", intensifica a sua função de produtor e de exportador de commodities, contribuindo para a participação do Brasil na atual divisão internacional do trabalho.A tradicional função vinculada à especialização produtiva em soja, carnes e couros, não apenas se mantém mas se revigora, em virtude da expansão da demanda por commmodities (ressalte-se que, segundo infor- 
mações do Dataviva, em 2016os referidos produtos ainda prevaleciam na pauta exportadora do município). A presença de empresas mundiais como Cargill, ADM, Brasil Foods,JBS Couros (e também da Braspelco, que atuou vários anos no município), é fundamental neste processo, desde que estas se inserem na atividade (agro)industrial uberlandense.É a relação local-global em sua plena expressão.

A partir de 2000, a expansão da agroindústria do município, se relaciona, portanto,ao aprofundamento da inserção brasileirano comércio global de commodities. Contudo, diante da conjuntura atual, nacional e internacional,de oscilação nos preços e na demanda de commodities, há que se pensar de que forma as atividades vinculadas ao agronegócio - tal como a agroindústria - terão continuidade nos próximos anos. E, neste contexto, quais serão as implicações para os espaços locais, tal como o de Uberlândia, cujas economias encontram-se fortemente articuladas ao comércio de commodities no mercado internacional.

\section{REFERÊNCIAS}

BRASIL. Ministério da Agricultura, Pecuária e Abastecimento (MAPA). Agrostat. Brasilia, 2016. Disponível em: <http://indicadores.agricultura.gov.br/agrostat/ index.htm.>Acesso em: 11 mar. 2016.

BRASPELCO inaugura a maior fábrica de couro do mundo. Diário de Cuiabá, 12 out. 2003. Disponível em: :<http://www.diariodecuiaba.com.br/detalhe.php?cod=156912.> Acesso em: 27 nov. 2015.

CENTRO de ESTUdos AVANÇAdos EM ECONOMIA APLICADA-CEPEA. PIB Agro. Escola Superior de Agricultura Luiz de Queiroz (ESALQ). Universidade de São Paulo.Disponível em: <http://www.cepea.esalq.usp.br/>. Acesso em dez. 2015.

CENTRO INDUSTRIAL E EMPRESARIAL DE MINAS GERAIS-CIEMG/FIEMG. Cadastro industrial de Minas Gerais, 2013.1 CD-ROM.

CLEPS JÚNIOR, J. Dinâmica e estratégias do setor agroindustrial no cerrado: o caso do Triângulo Mineiro. 1998, 291 f. Tese (Doutorado em Geografia) - Instituto de Geociências e Ciências Exatas, Universidade Estadual Paulista, Rio Claro, 1998.

DALLA COSTA, A. A Sadia e sua experiência no mercado internacional. Economia \& Tecnologia, Curitiba, ano 5, v. 16, jan./mar. de 2009, p. 151-166. Disponível em: <http://www.economiaetecnologia.ufpr.br/revista/16\%20Capa/Armando\%20Dalla\%20 Costa.pdf> Acesso em: 02 abr. 2016.

DATAVIVA. Data viva. Disponível em: <http://pt.dataviva.info/>Acesso em: fev. 2015/ 2016.

DELGADO, G. C. Do capital financeiro na agricultura à economia do agronegócio: mudanças cíclicas em meio século (1965-2012). Porto Alegre: Editora da UFRGS, 2012.

EMPRESAS DO BRASIL. Disponível em:<http://empresasdobrasil.com/>. Acesso em: mar. 2016

GRAZIANO DA SILVA, J. A industrialização e a urbanização da agricultura brasileira. São Paulo em Perspectiva: o agrário paulista, São Paulo, v. 7, n. 3, p. 2-10, 1993.

GUIMARÃES, E. N. Formação e desenvolvimento econômico do Triângulo Mineiro: integração nacional e consolidação regional. Uberlândia: EDUFU, 2010. 254p. 
INSTITUTO BRASILEIRO DE GEOGRAFIA E ESTATÍSTICA (IBGE). Cidades. Minas Gerais, Uberlândia - Produto Interno Bruto dos Municípios. 2013. Disponível em: <http:/ /cidades.ibge.gov.br/xtras/grafico_cidades.php?lang=\&codmun=317020\&idtema $=152 \&$ search $=$ minas-gerais $\mid$ uberlan $>$. Acesso em: 2016 .

Estimativas de população, 2017. Disponível em: <https://www.ibge.gov.br/ estatisticas-novoportal/sociais/populacao/9103-estimativas-de-populacao.html? = \&t=downloads $>$. Acesso em: ago. 2018.

INSTITUTO DE PESQUISA ECONÔMICA APLICADA (IPEADATA) Ipeadata regional. Agropecuária, 2015. Disponível em: <http://www.ipeadata.gov.br/>. Acesso em: maio.2015.

KAGEYAMA, A. et al. O novo padrão agrícola brasileiro: do complexo rural aos complexos agroindustriais. In: DELGADO, G.C; GASQUES, J.G.; VERDE, C.M.V.(Org.). Agricultura e políticas públicas. Brasília: IPEA, 1990. Cap. II.

MARTINS, H. E. de P. Periodização e análise do desenvolvimento industrial de Uberlândia segundo as tendências locacionais da indústria. Sociedade \& Natureza, Uberlândia, ano 12, n. 23, p. 63-79, jan./jun. 2000.

MÜLLER, G. O complexo agroindustrial brasileiro, Relatório no 13, Rio de Janeiro: Publicações FGV, 1981. 114 p.

O CAI brasileiro e as transnacionais e o CAI soja/indústria das oleaginosas. Relatório no 24, Rio de Janeiro: Publicações FGV, 1982. 79 p.

PEREIRA, M. F. V. Os agentes do agronegócio e o uso do território no Triângulo Mineiro/ Alto Paranaíba: da moderna agricultura de grãos à expansão recente da cana de açúcar. Revista do Departamento de Geografia, Universidade de São Paulo, São Paulo, v. 23, p. 83-104, 2012.

PESSÔA, V. L. S. Caracterização da modernização da agricultura e do desenvolvimento rural em Uberlândia. 1982. 175 f. Dissertação (Mestrado em Geografia) - Instituto de Geociências e Ciências Exatas, Universidade Estadual Paulista, Rio Claro, 1982.

SADIA compra a Granja Rezende por R\$134 milhões. Diário do Grande ABC, São Paulo, Economia, 28/12/1999. Disponível em <http://www.dgabc.com.br> Acesso em: 02 abr.2016.

SOARES, B.R. et al. Uberlândia (MG): leituras geográficas de uma cidade média em transição. In: ELIAS, D.; SPOSITO, M. E B.; SOARES, B. R (Org.) Agentes econômicos e reestruturação urbana e regional: Tandil e Uberlândia. São Paulo: Expressão Popular, 2010. p. 159-285.

Recebido em setembro de 2018 Aceito em novembro de 2018 